\title{
Effect of Scion Root Occurrence on the Flowering, Fruit Quality and Yield of 'Shiranuhi' Mandarin Hybrid in Plastic Film House
}

\author{
Seok-Beom Kang*, Young-Eel Moon", and Yong-Ho Kim \\ Citrus Research Station, National Institute of Horticultural \& Herbal Science, RDA, Seogwipo, 699-946, Korea \\ ${ }^{1}$ Agricultural Research Center for Climate Change, National Institute of Horticultural \& Herbal Science, \\ RDA, Jeju, 690-150, Korea
}

(Received: November 11 2013, Accepted: November 22 2013)

As most of citrus, shiranuhi mandarin ( (Citrus unshiu $\times C$. sinensis $) \times C$. reticulata) mainly use the trifoliate orange (Poncirus trifoliata) as its rootstock which has dwarf and cold hardness in Korea. However, recently, scion root was observed in 'Shiranuhi' mandarin tree grafted onto the trifoliate orange. This study was caried out to find out effects of scion root occurrence on the fruit quality, flowering and yield of shiranuhi mandarin. For the experiment, we selected six farmers who have outbreak of scion root in their Shiranuhi mandarin orchards and surveyed the difference of fruit quality of shiranuhi mandarin hybrid between scion root and control (trifoliate orange root). In the results, flowering was severely decreased in scion root trees compared to control. As a result of survey of 174 Shiranuhi mandarins, 160 trees were proved to be scion root, and had less flowering. Fruiting of scion root also severely dropped compared to control and thus, yields of scion root (6.4 $\mathrm{kg}$ ) reduced by $24 \%$ compared to control $(26.7 \mathrm{~kg})$. The fruit size, weight and soluble solid contents of scion root were significantly reduced, but there were no differences in acid contents and coloring of fruit. From the results, we concluded that scion root had negative influence on flowering, fruit size and the yields of Shrinanuhi mandarin hybrid.

Key words: Scion root, Shiranuhi mandarin, Fruit quality

Effect of scion root occurrence on the flowering of 'Shiranuhi' mandarin under plastic film house.

\begin{tabular}{|c|c|c|c|c|c|c|}
\hline \multirow{2}{*}{ Area } & \multirow{2}{*}{ Treatment } & \multicolumn{4}{|c|}{ Degree of flowering (flowering/tree) ${ }^{\mathrm{y}}$} & \multirow{2}{*}{$\begin{array}{c}\text { No. of tree } \\
\text { (ratio of scion root per total tree) }\end{array}$} \\
\hline & & $\mathrm{Non}^{\mathrm{z}}$ & Small & Medium & High & \\
\hline \multirow{2}{*}{ Gosan } & Scion root & 7 & 47 & 24 & 8 & $86(50.3 \%)$ \\
\hline & Control & 0 & 7 & 20 & 58 & $85(49.7 \%)$ \\
\hline \multirow{2}{*}{ Wimi } & Scion root & 160 & 14 & 0 & 0 & $174(80.6 \%)$ \\
\hline & Control & 0 & 22 & 15 & 5 & $42(19.4 \%)$ \\
\hline
\end{tabular}

${ }^{\mathrm{z}}$ Non (below 10 flowering), Small (11 100), Medium (101 1000), High (over 1000)

${ }^{\mathrm{y}}$ Date: 1 May 2012 


\section{Introduction}

자근 (自根, scion root)이란 부지화 감귤나무가 재식시 땅속에 깊게 묻혔을 때 접목부위 위에서 접수인 부지화의 뿌리가 발생된 것을 말하며 최근 제주도 부지화 (한라봉) 재 배지를 중심으로 자근 발생에 따른 피해가 급증하고 있다. 과수는 고품질의 과실 생산, 안정적인 양-수분 공급, 내한성 증진과 수세강화 등을 위하여 대목을 이용하는데 부지화 감 귤도 다른 감귤들과 마찬가지로 주로 탱자를 대목으로 이용 하고 있다 (Ferguson et al., 2010).

이전까지 탱자를 대목으로 한 온주밀감 감귤재배에서는 이러한 자근발생이 없었고 따라서 자근에 대한 문제는 제주 감귤재배에서 전혀 없었다. 그러나 부지화 감귤나무는 농가 들 사이에서 고소득 작물로 인식되면서 하우스내에 부지화 를 재배시 묘목이 잘 자라도록 깊게 심고 재배 중에도 잦은 배토를 하여 세력을 강화시키는 재배습관에 의해 자근 발생 이 더욱 증가하였다. 부지화가 제주도에서 재배되기 시작된 1990년대 후반부터 지금까지 자근 문제가 농가들 사이에서 발견되고 문제가 되기 시작한 것은 2007년 이후 부터이며 나무의 세력이 강하고 착화가 해거리와는 다르게 2 년 이상 불량했던 부지화 감귤나무들에 대한 조사에서 자근 발생이 확인되었다 (Kang et al., 2012).

Ferguson et al (2010)는 감귤에서는 자근묘를 이용하게 되면 내한성, 내병성, 및 토양적응성 등 다양한 대목의 특성 들을 이용할 수 없어 대다수의 감귤에서는 자근묘를 이용하 지 않는다고 하였는데 그러한 이유는 Halma (1947)의 보고 에서처럼 유레카 레몬을 자근묘로 키웠을 때 스위크오렌지 와 크래프르트 대목을 이용한 접목묘에 비해 나무의 충실도 및 생산성이 낮아지기 때문이다.

부지화와 천초 감귤에서 자근이 발생된 나무는 정상나무 에 비해 나무의 세력이 강해지고 그로 인해 착화량 감소로 수량이 저하된다는 보고가 일본에서 근래에 있었으나 이에 대한 국내의 연구결과는 없는 실정이다 (Hirano et al., 2002; Hiroshi et al., 2004; Kawasoe, 2007). 현재까지 자근발생 이 보고된 감귤 품종으로는 '천초', '세토카', '부지화' 이며 노지재배에서 보다는 하우스 재배에서 발생이 더 잘되는 것 으로 알려져 있다.

부지화 감귤은 상품성이 좋은 과일일수록 과중이 커야 하는데 이렇게 큰 과실을 결실시키기 위해서는 나무의 세력 을 강하게 키워야 한다. 그러나 이렇게 강한 나무의 수세를 유지하기 위해 무리하게 나무를 깊게 심고 배토하며 퇴비나 질소비료 들을 과다하게 시용함에 따라 나무는 생리적으로 착화가 불량해지는 영양생장으로 치우쳐 자근도 더 쉽게 발 생되는 환경에 놓이게 되었다. 밀식재배 사과에서도 기계화 작업에 의해 묘목을 깊게 심은 곳에서는 접목부위가 지면에 묻힌 곳에서 자근이 발생되었고 이러한 나무는 세력이 너무
강하여 조기에 수관이 커져 밀식재배도 못하고 착화도 불량하 여 농가에 수량저하를 미치고 있다는 보고가 있다 (Warner, 2009)

따라서 본 연구는 최근 제주도내에서 문제시되고 있는 자근 발생이 부지화 감귤의 착화, 과실품질 및 수량에 미치 는 영향을 밝혀 자근발생 나무에 대한 기초자료를 얻고 그 에 맞춰 자근이 발생된 부지화 감귤나무에 대한 관리대책을 마련하기 위해 수행하였다.

\section{Materials and Methods}

착화량 및 착과량 조사 부지화 감귤나무의 착화량 조 사를 위해 제주특별자치도 서귀포시 고산리와 위미리에 위 치한 2 개 지역의 탱자를 대목으로 한 15 년생 부지화 감귤원 에서 자근발생 나무와 정상나무간의 봄철 착화량을 2012년 5 월 1 일에 조사 하였다. 착화량은 자근 발생나무와 정상나무 로 구분을 한 후 수상에 달린 착화정도를 꽃이 0 개에서 1000 개 이상까지를 등급화 (없음 (Non): 0 10개 이내, 소 (Small): 11 100개, 중 (Medium): 101 1000개, 다 (High): 1000 개 이상)하여 착화량을 조사하였다.

부지화 자근발생 나무와 정상나무간의 착과량 조사를 위 해 서귀포시에 위치한 부지화 재배농가 6곳을 선정하여 농 가당 자근발생 나무 50주와 정상나무 50주에 대해 2012년 7 월 10 일에 조사 하였다. 착과량은 나무당 착과량 정도를 과 실이 0과에서 100 과 이상까지를 등급화 (없음 (Non): 0 10 과 이내, 소 (Small): 11 50과, 중 (Medium): 51 100과, 다 (High): 100 과 이상)하여 착과량을 조사하였다.

과실품질 및 수량 조사 부지화 자근발생에 따른 과실 품질과 수량에 미치는 영향을 조사하기 위해 착화량 조사를 한 서귀포시 남원읍 위미리에 위치한 15 년생 부지화 나무를 정상나무 10 주와 자근발생 나무 10 주를 선정하여 과실품질 과 수량조사를 하였다. 수확일에 채취된 과실은 반복별로 10 과씩을 선정하여 과실의 횡경과 종경을 버니어캘리퍼스를 이용하여 측정하였다. 착색도는 색차계 $(\mathrm{CR}-400$, Minolta, Japan)을 이용하여 각각 과실의 적도면 3곳을 Hunter's L, $\mathrm{a}, \mathrm{b}$ 값으로 측정 후 평균하여 이용하였다. 과실의 과중과 과육중은 10 과에 대해 개별적으로 과중을 측정 후 과피를 벗겨 과육중을 측정하였다. 과피두께는 각각의 과실 껍질을 4 개를 모아 버니어캘리퍼스로 측정 후 환산하였다. 과실의 당함량과 산함량 측정을 위해 과육 시료를 착즙 후 당함량 은 굴절당도계 (PR-101, Atago, Japan)를 이용하여 측정하 였으며 산함량은 $5 \mathrm{~mL}$ 의 과즙에 증류수 $20 \mathrm{~mL}$ 를 넣고 0.1 $\mathrm{N} \mathrm{NaOH}$ 를 이용하여 $\mathrm{pH}$ 8.1이 되는 점에서 산적정을 하여 구연산으로 환산하였다. 수량조사는 수확일 (2013년 1월 14 일)에 실험에 이용된 나무마다 과실을 전부 수확 후 과실 개 
수와 무게를 처리별로 전수 조사하였다.

통계분석 본 시험에 이용된 자료에 대해서는 SAS Enterprise Guide 3.0 을 이용하여 $\mathrm{t}$-검정 $(\mathrm{p}=0.05)$ 으로 처리간의 유의 성을 분석하였다.

\section{Results and Discussion}

본 연구는 제주특별자치도 부지화 재배농가를 중심으로 최근 발생되는 자근이 착화량과 과실품질에 미치는 영향을 조사하기 위하여 수행하였다. 15 년생 부지화를 재배하는 과 원중 자근발생이 의심되는 과원을 지역별로 2 곳을 선정하 여 자근발생 여부와 봄철 착화량을 조사한 결과는 Table 1 에 나타내었다. 조사결과 2 지역 모두에서 자근발생이 관찰 되었으며 발생비율은 고산에서는 과원 나무의 절반인 $50.3 \%$ (171주중 86주)에서 자근발생이 관찰되었으나 위미에서는 80.6\% (216주중 174주)로 심한 곳에서는 대부분의 부지화 나무에서 자근이 발생된 것으로 확인되었다.

이들 과원에서의 자근발생이 착화량에 미치는 영향을 확 인하기 위해 착화량 정도에 따라 등급을 매겨 조사한 결과 꽃 발생이 10 개 미만인 나무의 비율을 보면 자근발생 나무 는 고산에서는 자근나무 86주중 7 주가, 위미에서는 자근나 무 174주중 170 주가 꽃 발생이 10 개 미만인 나무로 조사되 었다. 반면 조사기준에서 적정 착과량을 '중' (101 1000화) 으로 하였을 때 고산에서는 착화량이 '중' 이상 되는 나무는 자근나무의 86 주중 32 주 밖에 되지 않았고 위미에서는 174 주의 조사주 중 한주도 '중' 이상의 착화량을 갖는 나무가 없었다. 반면, 고산에서의 정상나무 착화량은 85 주의 조사 주중 78 주가 '중' 이상의 착화량을 보였으며 위미에서도 42 주의 정상나무 중 20 주가 '중' 이상의 착화량을 보여 자근발 생 나무와 정상나무간에는 착화량이 크게 차이가 나고 있음 을 확인할 수 있었다.

이렇게 착화량에서 자근발생나무와 정상나무간의 큰 차 이가 발생된다는 것은 결국 농가에는 착과 감소에 따른 수 량 저하를 초래할 수 있다는 의미로 매우 심각한 문제를 야 기시킬 수 있음을 알 수 있었다.
Table 1 에서 자근발생이 부지화 감귤나무의 착화량에 커 다란 영향을 미치는 것을 확인하여 부지화 감귤재배의 주산 지인 서귀포시에서 부지화 재배 농가 6곳을 무작위로 선정 하여 농가당 정상나무와 자근발생 나무를 50 주씩 선정하여 착과량을 조사하였다 (Fig. 1). 조사결과 적정 착과량을 주 당 51 100과로 등급화 했을 때 자근발생 나무는 10과 이내 의 착과량이 $34 \%, 10 \sim 50$ 과 이내의 착과량이 $45 \%$ 로 전체 착 과량의 $79 \%$ 가 과실이 적게 달리거나 없는 수준으로 나타났 으며 이에 반해 정상나무는 51 100과 이내의 착과량이 $41 \%$, 100 과 이상의 착과량이 $32 \%$ 로 자근발생 나무와 정반대의 착과경향을 나타내고 있었다. 이러한 결과는 농가의 소득과 직결되는 문제로 착과가 되더라도 착과량이 정상나무에 비 해 현저히 떨어져 수량이 감소되고 있음을 나타내는 것으로 현재 자근발생이 부지화 재배 농가에 많은 피해를 미치고 있음을 알 수 있었다. 이러한 자근발생에 따른 부지화의 착화 및 착과량 감소는 Hirano et al. (2002)와 Kawasoe (2007)의 보고와 일치하는 결과로 제주에서 자근 발생이 부지화 재배 에서 심각해지고 있음을 나타낸다고 하겠다.

부지화에서 자근발생이 과실품질에 미치는 영향은 Table 2 에 나타내었다. 정상나무에 비해 자근발생 나무에서는 과 실의 종경크기는 처리간 차이가 없었으나 횡경에서는 7.9

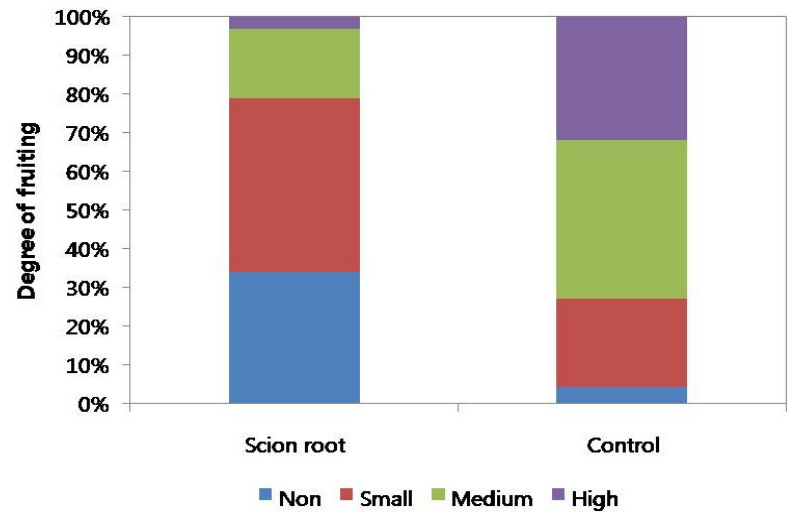

Fig. 1. Effect of scion root occurrence on the fruiting of Shiranuhi mandarin in plastic film house.

${ }^{\mathrm{z}}$ Non: below 10 fruit, Small: 10 50 fruit, Medium: 51 100 fruit, High: over 100 fruit, yDate: 10 July 2012.

Table 1. Effect of scion root occurrence on the flowering of Shiranuhi mandarin in plastic film house.

\begin{tabular}{ccccccc}
\hline \hline \multirow{2}{*}{ Area } & Treatment & \multicolumn{3}{c}{ Degree of flowering (flowering/tree) } & \multicolumn{2}{c}{$\begin{array}{c}\text { No. of tree } \\
\text { (ratio of scion root to total tree) }\end{array}$} \\
\cline { 3 - 6 } Gosan & Non $^{\mathrm{z}}$ & Small & Medium & High & $86(50.3 \%)$ \\
& Scion root & 7 & 47 & 24 & 8 & $85(49.7 \%)$ \\
\hline \multirow{2}{*}{ Wimi } & Control & 0 & 7 & 20 & 58 & $174(80.6 \%)$ \\
& Scion root & 160 & 14 & 0 & 0 & $42(19.4 \%)$ \\
\hline
\end{tabular}

${ }^{\mathrm{z}}$ Non (below 10 flowering), Small (11 100), Medium (101 1000), High (over 1000)

${ }^{\mathrm{y}}$ Date: 1 May 2012 
Table 2. Effect of scion root occurrence on the fruit quality of 'Shiranuhi' mandarin in plastic film house.

\begin{tabular}{ccccccccccccc}
\hline \hline Treatment & $\begin{array}{c}\text { Fruit } \\
\text { Diameter } \\
(\mathrm{mm})^{\mathrm{y}}\end{array}$ & $\begin{array}{c}\text { Fruit } \\
\text { Longitudinal } \\
(\mathrm{mm})\end{array}$ & $\begin{array}{c}\text { Fruit } \\
\text { weight } \\
(\mathrm{g})\end{array}$ & $\begin{array}{c}\text { Ratio of } \\
\text { flesh } \\
(\%)\end{array}$ & $\begin{array}{c}\text { Peel } \\
\text { thickness } \\
(\mathrm{mm})\end{array}$ & $\begin{array}{c}\text { SSC } \\
\left({ }^{\circ} \text { Brix }\right)\end{array}$ & $\begin{array}{c}\text { Acid } \\
\text { contents } \\
(\%)\end{array}$ & $\begin{array}{c}\text { Ratio of } \\
\text { S/A }\end{array}$ & \multicolumn{2}{c}{ Hunter's } & a & b \\
\hline Control & $82.4^{\mathrm{z}}$ & 84.1 & 251.1 & 74.4 & 4.0 & 13.9 & 1.1 & 13.0 & 69.3 & 23.3 & 71.0 \\
Scion root & 74.5 & 82.2 & 200.8 & 71.5 & 4.2 & 12.5 & 1.2 & 10.2 & 69.2 & 22.3 & 71.4 \\
t-test & $0.0157^{*}$ & 0.5168 & $0.0339^{*}$ & 0.1723 & 0.2567 & $0.0125^{*}$ & 0.1045 & $0.0132^{*}$ & 0.9251 & 0.3830 & 0.5551 \\
\hline
\end{tabular}

$\mathrm{z}_{\text {t-test }}$ at $\mathrm{P}=0.05$

${ }^{\mathrm{y}}$ Date: 14 January 2013

Table 3. Effect of scion root occurrence on the Yield of 'Shiranuhi' mandarin in plastic film house.

\begin{tabular}{ccc}
\hline \hline Treatment & No. of fruit $(\mathrm{ea} / \text { tree })^{\mathrm{y}}$ & Yield $(\mathrm{kg} /$ tree $)$ \\
\hline Control & $112.8^{\mathrm{z}}$ & $26.7 \mathrm{a}$ \\
Scion root & 28.7 & $6.4 \mathrm{~b}$ \\
t-test & $0.0054^{* *}$ & $0.0025^{* *}$ \\
\hline
\end{tabular}

${ }^{\mathrm{z}}$-test at $\mathrm{P}=0.05$

${ }^{\mathrm{y}}$ Date: 14 January 2013

$\mathrm{mm}$ 가 적었으며 처리간 유의차를 나타냈다. 과중에 있어서 도 정상나무의 $251 \mathrm{~g}$ 에 비해 자근발생 나무에서는 $201 \mathrm{~g}$ 으로 자근발생 나무에서 과실이 $50 \mathrm{~g}$ 감소하는 유의한 결과를 나 타냈다. 자근발생에 따른 당함량에서는 정상나무의 $13.9^{\circ} \mathrm{Bx}$ 에 비해 자근나무에서는 $12.5^{\circ} \mathrm{Bx}$ 로 $1.4^{\circ} \mathrm{Bx}$ 가 당함량이 유의 하게 감소하였으나 산함량에 있어서는 처리간 유의차는 나 타나지 않았다. 그로 인해 과실의 맛을 나타내는 당산비는 정상나무가 13.0 을 나타냈으나 자근발생 나무는 10.2 를 나 타내어 자근발생이 과실의 식미도를 $22 \%$ 떨어뜨려 상품성 을 저해하고 있음을 알 수 있었다. 한편, 착색에 미치는 자 근의 영향은 처리간 무의한 것으로 확인되었다. 이렇게 자 근 발생에 따른 감귤 과실의 당함량 저하에 대해서는 천초 (Hirano et al., 2002)와 부지화 (Kawasoe, 2007)에서도 보 고되고 있으나 산 함량에 있어서는 천초 감귤에서는 자근 발생에 따라 산 함량이 낮아지는 것으로 보고되었으나 부지 화 감귤에 있어서는 뚜렷한 경향을 나타내지 않았다.

자근발생에 따른 과실 수량에 미치는 영향은 Table 3에 나타내었다. Table 1과 Fig. 1에서 살펴본 바와 같이 착화량 과 착과량에 미치는 자근의 영향은 뚜렷하였으며 그러한 결 과가 수량에 미치는 영향은 과실 수확일에 분명하게 나타났 다. 조사결과 대조구인 정상나무의 주당 착과량은 113 개 였 으나 자근발생 나무는 29 개로 정상나무의 $25.4 \%$ 수준으로 감소하였으며 주당 수량에 있어서는 정상나무의 $26.7 \mathrm{~kg}$ 에 비해 자근발생 나무에서는 $6.4 \mathrm{~kg}$ 로 정상나무의 $24 \%$ 수준 으로 떨어졌다. 이렇게 자근발생에 의한 수량감소에 대해 Hirano et al. (2002)는 천초 감귤에서 7 8년생때 자근발생에 의해 수량감소가 유의하게 나타났다고 보고하였는데 이러한 결 과는 본 연구결과와 일치하는 결과로서 정상나무에 비해 자
근발생 나무에서 수량이 4 배 가량 감소하였다는 것은 수확 시 자근에 의한 과중 감소 및 당함량 저하와 더불어 부지화 재배에서 자근발생 문제가 부지화 농가의 피해를 더욱 증가 시킨다고 할 수 있다.

\section{Conclusion}

본 연구의 결과를 통해서 살펴보면 부지화 감귤에서 자 근은 현재 제주도내에서 지속적으로 발생되고 있으며 자근 이 발생됐을 때는 나무의 수체 생리가 교란되어 착화불량에 의한 착과량 저하가 발생되고 그로 인해 과실은 크기가 작 아져 과중은 감소하고 당함량이 떨어져 작고 맛없는 과실이 생산되는 문제를 일으키고 있다. 이는 과거 온주밀감 재배 시 잘못된 재배습관으로 만감류인 부지화 감귤을 재배함에 따라 발생된 문제로서 접목재배를 하는 과수는 무엇보다 재 배시 대목노출이 중요하다는 교훈을 되새겨 준다고 할 수 있다. 앞으로 자근에 대한 발생 방지, 피해경감 및 수량개선 등에 대한 많은 연구들이 뒤따라야 하겠지만 자근발생시 수 체에 미치는 영향을 제대로 알고 그에 따른 자근 발생 방지 를 위한 연구와 대책마련이 시급히 이루어져야 할 것으로 판단된다.

\section{References}

Ferguson, J.J., J. Charparro, and T.M. Spann, 2010. Dwarfting and freeze hardiness potential of trifoliate orange rootstocks. Unv. of Florida. IFAS Extension. HS 982. p. 1-6.

Harma F.F. 1947. Own-rooted and budded lemon trees. Calif. 
Citrog. 33:1-15

Hirosi, F., H. Rikiya., N. Ryutarou., Sugita T. and T. Kinosita. 2004. Characteristics of citrus cultivar 'Amakusa' in the occurrence of scion roots. Kyushu agricultural research, Vol 66, p. 238.

Hirano, M.H., S. Gousagu, and T. Shindo. 2002. Influence of the occurrence of scion root on the growth and fruit quality of 'Amakusa' mandarin. Kyushu agricultural research 64:207-207.

Kang, S.B., Y.E. Moon, D.H. Lee, Y.H. Kim, S.G. Han, and C.W. Chae. 2012. Outbreak of Scion Root from 'Shiranuhi
Mandarin' Hybrid Tree in Plastic Film House. Korean J. Environ. Agric. 31(4):313-317.

Kawasoe, K. 2007. Countermeasure and outbreak of scion root in 'Shiranuhi' mandarin. Izumi Agricultural Improvement and Advisory Center. p. 1.

Platt, R.G., Opitz, K.W. 1978. Propagation of citrus - The citrus industry. University of California, Volume IV. p. 31-45.

Warner G. 2009. Avoid scion rooting - Scion rooting eliminates the dwarfing effect of the rootstock. Good Fruit Grower. January $15^{\text {th }}$. p. 1-4. 